\title{
Water movement, oxygen supply and biological processes on the aggregate scale
}

\author{
P.A. Leffelaar \\ Department of Theoretical Production Ecology, Wageningen Agricultural University, P.O. Box 430, \\ 6700 AK, Wageningen, The Netherlands
}

(Received November 27, 1991; accepted after revision July 1, 1992)

\begin{abstract}
Leffelaar, P.A., 1993. Water movement, oxygen supply and biological processes on the aggregate scale. In: L. Brussaard and M.J. Kooistra (Editors), Int. Workshop on Methods of Research on Soil Structure/Soil Biota Interrelationships. Geoderma, 57: 143-165.
\end{abstract}

An experimental respirometer system and a theoretical simulation model were developed to study the dynamics of water movement, oxygen supply and biological processes on the aggregate scale in unsaturated soil.

The experimental system enables one to measure simultaneously the distribution of water, oxygen, and chemical substances as a function of space and time in an unsaturated, artificially made, homogeneous, cylindrical aggregate and the changes in atmospheric composition as a function of time in the chamber that contains the aggregate. Non-destructive measurements during an experiment involve gamma ray attenuation, gas chromatography and polarography. Destructive measurements are performed at the end of an experiment in the form of chemical analyses of soil.

The theoretical model enables one to calculate simultaneously the distribution of water, bacteria, gases (e.g. oxygen, carbon dioxide and molecular nitrogen), absolute soil atmospheric pressure and solutes (e.g. nitrate and glucose) as a function of space and time for exactly the same cylindrical geometry as in the experimental set up. Also, the changes in atmospheric composition as a function of time in the chamber that contains the aggregate are calculated. Except for water transport, all processes are caused by microbial activity, since roots are absent in the aggregate.

The respirometer system was designed to generate coherent data sets to evaluate the simulation model, while the model was needed to more completely interpret the data obtained from the experiments.

The reported experiment shows that hysteresis in the soil water characteristic strongly affects the water distribution in the aggregate. As a result, the oxygen supply to the interior of the aggregate is decreased to such an extent, that anaerobiosis is maintained there after the oxygen is consumed.

The respiratory quotient (RQ) was about one in the experiment, although one would expect larger values in partially anaerobic soil. Therefore, the RQ does not seem a sensitive measure to decide whether a soil is partially anaerobic. Nevertheless, the consumption rate of oxygen and the production rate of carbon dioxide compared well with field data. This is the result of the pretreatment of the soil, which aimed at avoiding the flush of microbial activity upon wetting.

The simulated results showed a satisfactory agreement with the experimental data: part of the ex-

Correspondence to: P.A. Leffelaar, Department of Theoretical Production Ecology, Wageningen Agricultural University, P.O. Box 430, 6700 AK, Wageningen, The Netherlands.

0016-7061/93/\$06.00 C 1993 Elsevier Science Publishers B.V. All rights reserved. 
perimental results could be described quantitatively, whereas other data that deviated from the experimental data could be understood by studying the dynamic behaviour of the model. Hysteresis in the soil water retention curve resulted in low values of the gas-filled porosities in the outer shell of the partially wetted aggregate, permitting gaseous exchange only through the water phase of soil. As a result anaerobiosis occurred. The model is very sensitive for the so-called critical gas filled porosity below which no gas-continuous pores exists. The simulated respiratory quotient was seen to be strongly affected by transport processes. Therefore, also on theoretical grounds it was concluded that RQ is not a sensitive indicator of partial anaerobiosis in soil.

The objective of this paper is to describe both the experimental respirometer system and the theoretical simulation model, and to report some of the measurements.

\section{INTRODUCTION}

In aggregated soils, intra- (micro) and interaggregate (macro) pores may be found. Both types of pores determine the transport properties of the soil for water, solutes and gaseous substances. As a result they determine the biological activity of the soil. The macro pores are a major determinant in the transport of substances through the soil from and to the atmosphere, whereas the micro pores are important in the transport of substances from the larger pores in the soil into and out of the aggregates, structural elements, or more generally, the denser structures in the soil.

Soils accommodate roots and fauna: the roots and the larger animals may contribute to the soil's macro pore system, while the microorganisms usually are fixed in their environment and act as small factories that transform substances passing by. The roots and the larger animals need oxygen for their life processes. Roots may have aerenchyma enabling them to live in water-saturated soil where oxygen is absent. The larger animals are bound to live above the ground water table in the macro pores and the cracks of the soil, which are partly created by them. The microorganisms, however, may be highly adapted to their environment: different species may live under strict aerobic circumstances, or under strict anaerobic circumstances, while some species may live in both of these environments.

In aggregated unsaturated soils, oxygen consumption potentially leading to anaerobiosis is mainly confined to the aggregates. Figure 1 depicts some schematic oxygen and water distributions as expected in field aggregates under the assumption of a homogeneous distribution of bacteria and organic compounds. When the oxygen consumption rate does not exceed the oxygen supply rate, anoxic conditions will not develop, and equimolar respiration occurs, as indicated by arrows (Fig. 1a). Just after rainfall, mainly the outer shell of an aggregate will be wetted (Leffelaar, 1979). The oxygen diffusion rate in the outer shell is then seriously impeded, and when the oxygen consumption rate exceeds the oxygen supply rate, anoxic conditions arise locally (Fig. 1b). In the center of the aggregate respiration continues to take place until the oxygen from the enclosed air has been consumed. Then most of the aggregate volume is anaerobic, and anaerobic processes can occur very near 


\section{soil aggregate}

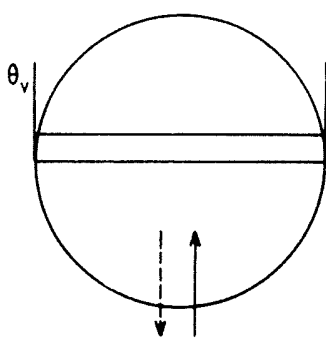

a.

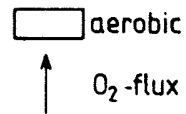

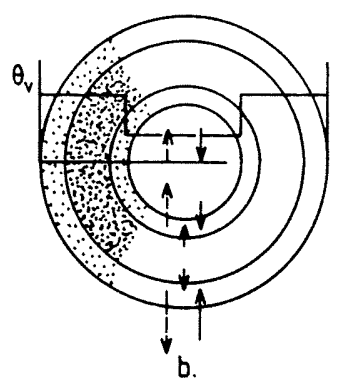

$\therefore \therefore$ transition zone
$\hat{i} \mathrm{CO}_{2}$-flux

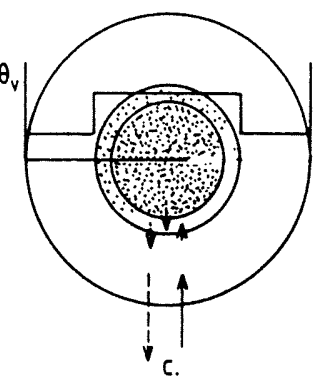

inis anaerobic

Fig. 1. Schematic water and oxygen distributions in soil aggregates: (a) in a dry period, (b) just after a rain shower, (c) some time after rainfall. Lengths of arrows indicate relative magnitudes of molar source or sink terms.

to aerobic processes in the outer shell. Subsequent redistribution of water may result in a decrease of the anaerobic aggregate volume, and hence of anaerobic processes, when the water content in the wetted shell becomes low enough to give continuous gas-filled pores permitting rapid oxygen diffusion into the aggregate. The distribution of oxygen in Fig. $1 \mathrm{c}$ will be found in initially watersaturated aggregates that are drying. Upon further drying their oxygen distributions will adjust to that of Fig. 1a.

These complicated dynamic interactions between biological and physical processes determining the oxygen status of soil and hence the occurrence of aerobic and anaerobic processes at the micro scale were studied both experimentally and theoretically. For the experimental study a respirometer system was developed that enables us to generate coherent data sets on water and gas movement and biological processes occurring on the micro scale. For the theoretical study, an explanatory simulation model was developed that includes descriptions of these processes. In fact the experimental system was developed to evaluate the theoretical model, while the theoretical model was needed for a more complete interpretation of the measured data.

The objective of the present paper is to describe the experimental respirometer system, to discuss the explanatory simulation model, and to compare the results of an experiment with those of the model.

\section{MATERIALS AND METHODS}

The experimental soil aggregate on which the measurements of the spatial distribution of oxygen, water, and decomposable organic compounds as a 


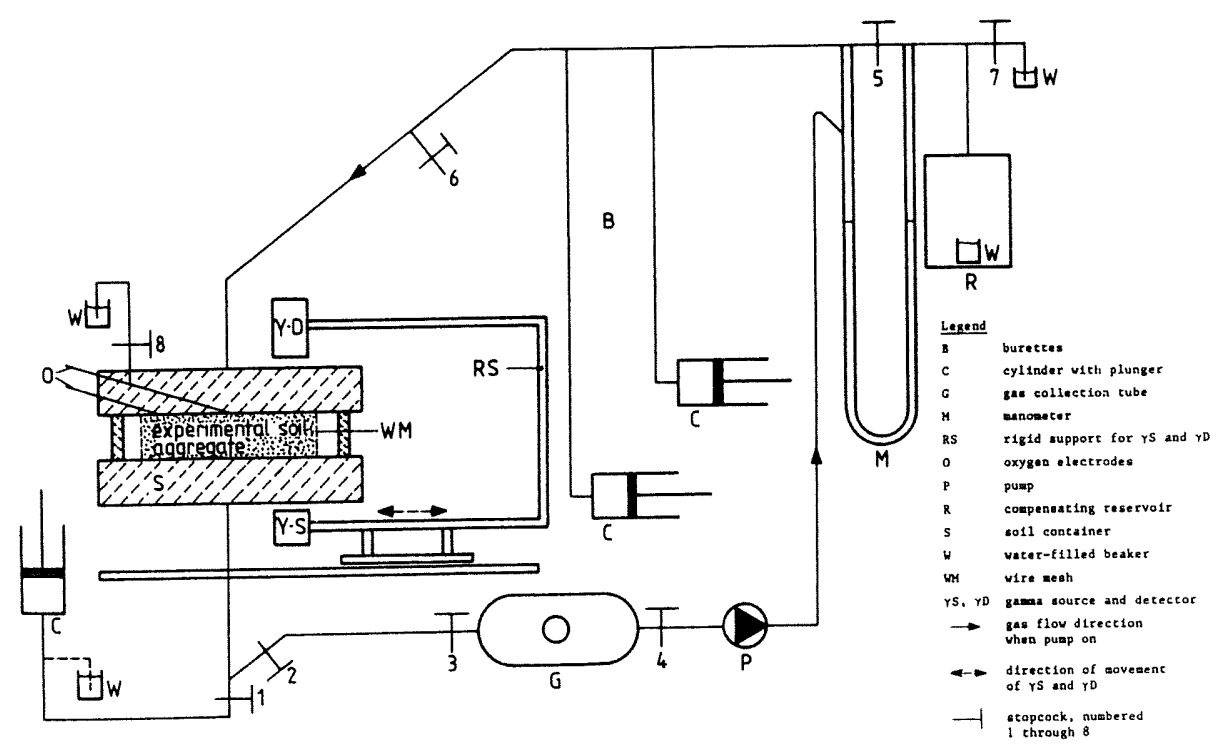

Fig. 2. Diagram of respirometer system showing soil container, gas collection circuit (stopcocks 1 through 7 and attached devices), oxygen electrodes and gamma ray attenuation apparatus with rigid support.

function of time are performed, is a short cylinder of homogeneously packed soil material in which transport processes are radial. This model representation of a soil aggregate originates directly from Fig. 1. A scheme of the experimental installation is given in Fig. 2.

Soil

A sandy loam soil from Lelystad was taken from the surface $0-25 \mathrm{~cm}$ layer and stored under field moist conditions. Some characteristics are: $\mathrm{pH}$ (measured in 4 gram of soil suspended in $10 \mathrm{ml}$ of liquid) in $\mathrm{H}_{2} \mathrm{O}$ and $\mathrm{KCl}: 7.8$ and 7.4, respectively; $\mathrm{CaCO}_{3}$ (Scheibler's method described by Allison and Moodie, 1965): 6\%; organic carbon (Mebius, 1960): 1.2\%; total nitrogen (Novozamsky et al., 1984): 0.09\%; CEC-BaCl ${ }_{2}$ (Bascomb, 1964): 10.1 cmol ( + ) per kg of soil; and soil texture (Pipette method described by Day, 1965) $2 \mu \mathrm{m}, 20 \mu \mathrm{m}$ and $50 \mu \mathrm{m}: 13,27$ and $32 \%$, respectively. The soil is airdryed, pulverized to pass a $0.5 \mathrm{~mm}$ sieve, directly remoistened to about $0.1-$ $0.15 \mathrm{~g} \mathrm{~g}^{-1}$ and left in a closed container for at least 6 weeks to let the metabolism of microorganisms recover (Birch, 1958, 1959; Fillery, 1983). Remoistening is attained by adding an appropriate amount of ice scrapings to soil and mixing in a mortar with a pestle. After installing the experimental aggregate in the measuring system, it is left alone for at least a week to let the me- 
tabolism of the microorganisms recover. Then, an experiment is started. This pretreatment of the soil effectively prevented the flush of microbial activity upon wetting.

\section{Measuring system}

The measuring system (Fig. 2) was installed in a constant temperature room $\left(22.7 \pm 1.5^{\circ} \mathrm{C}\right)$ and is composed of four subsystems:

(1) Container (S) which holds the experimental soil aggregate and the oxygen electrodes.

(2) A closed gas collection circuit (stopcocks 1 through 7 and attached devices) which serves three purposes:

- it contains enough oxygen to meet the respiratory demand of the microorganisms in the soil aggregate during one experiment.

- it functions as volumeter to determine net changes in the total volume of gas resulting from respiration.

- it is used to withdraw gas samples to assess gaseous composition by gas chromatography.

(3) Two polarographic Clark-type oxygen electrodes (Kreuzer et al., 1980) to measure oxygen pressure in the center and $4 \mathrm{~cm}$ from the center of the experimental soil aggregate.

(4) A gamma ray (60 keV radiation from ${ }^{241} \mathrm{Am}$ ) attenuation apparatus (resolution of $1 \mathrm{~mm}$ ) (De Swart and Groenevelt, 1971) to measure the radial distribution of soil water content.

The soil sample of $10 \mathrm{~cm}$ diameter and a height of $2.5 \mathrm{~cm}$ has a density of about $1.4 \mathrm{~g} \mathrm{~cm}^{-3}$, and is radially supported by a wire mesh of more than $70 \%$ porosity. The compensation reservoir, $\mathrm{R}$, serves to minimize the influence of barometric pressure changes. Pressure differences between the gas circuit and the compensation reservoir are eliminated by adjusting the water levels in the burettes $\mathrm{B}$. The change in burette volume is a measure for the net change in gas volume due to respiration in the soil aggregate. The gases in the gas collection circuit are thoroughly mixed by pump $\mathrm{P}$, before a gas sample is taken from gas collection tube G. Gas samples of $0.1 \mathrm{ml}$ were analysed on a Packard-Becker 427 gas chromatograph using Porapak Q and Molecular Sieve 5A columns in series and a thermal conductivity detector. The Clark-type electrodes were selected for their small oxygen consumption, compared with that of soil, and their good stability and linearity over 1 to 7 days of use.

In a typical experiment, the effect of a rain shower on the aggregate was mimicked by wetting the aggregate with a small amount of solution containing potassium nitrate and organic matter (glucose) equivalent to about $65 \mathrm{~kg}$ $\mathrm{ha}^{-1}(\mathrm{~N}$ and $\mathrm{C})$. Then, the redistribution of water and the dynamics of gases inside and outside the aggregate were recorded. At the end of the experiment the aggregate was partitioned into five concentric layers of $1 \mathrm{~cm}$ thickness 
each, in which gravimetric moisture content and chemical analysis (no data reported here) were determined.

Reliability of the data so obtained was assessed by calculating the propagation of the errors in the measured quantities on the final results by procedures outlined by Berendts et al. (1973). To this purpose, the errors in the measured quantities were evaluated from knowledge about the measuring instruments.

Full technical details, comments on procedures and calculations to obtain the data are given in the work by Leffelaar (1986).

SIMULATION MODEL COMPRISING SUBMODELS FOR RESPIRATION, WATER, SOLUTES, AND GASES

An explanatory simulation model was developed for the same geometry as depicted in Fig. 2 to calculate the distribution of the relevant state variables, here bacteria, water, solutes, and gases, as a function of space and time in an unsaturated aggregate in which transport processes are radial. Also the changes in atmospheric composition as a function of time, in the chamber that contains the aggregate, are calculated.

The simulation model comprises four submodels: one for the biological process of respiration and denitrification, and three for the transport processes of water, solutes (decomposable organic compounds, i.e. glucose), and gases (e.g. oxygen, carbon dioxide and molecular nitrogen), respectively. To calculate the spatial distribution of the various state variables, the system was divided into a number of concentric layers (Frissel and Reiniger, 1974; De Wit and van Keulen, 1975). The interactions between the system components are reflected in the interactions between the four submodels. This may be demonstrated by the equation of continuity, eq. (1), that is solved for each mobile substance in each layer:

$\frac{\partial C_{i}}{\partial t}=-\frac{\partial J_{i}}{\partial x}+P_{i}$

Symbols are defined in the Appendix. For instance, the respiration submodel calculates different gas production and consumption rates $\left(P_{i}\right)$ in adjacent aggregate layers, because the bacteria in these layers are subjected to different environmental conditions. Different production and consumption rates result in gradients in the concentration of substance $i$. When it concerns a gaseous substance, in principle also gradients in absolute pressure result. The flux $J_{i}$ includes the diffusive, dispersive and mass flow components. Integration of eq. (1) with respect to time will give the time course of substance $i$ in a layer as a result of the interactions of microbial activity and physical transport processes. When a substance is inert, e.g. molecular nitrogen, or 
immobile, e.g. biomass, the production term or the flux term in eq. (1) equals zero.

To develop the submodels, numerous assumptions had to be made. Many of these assumptions have been described elsewhere: the respiration and denitrification model by Leffelaar and Wessel (1988); the water flow model by Dane and Wierenga (1975); the solute transport model by Bolt (1979); and the gas transport model by Leffelaar $(1987,1988)$. Therefore, these models and their assumptions are merely summarized below. However, the interactions between the submodels of the water with the gases, and with the gas production and consumption terms due to respiration, imposed difficulties that are not normally envisaged when such models are developed or used separately. Therefore, these are mentioned in somewhat more detail.

\section{Respiration submodel}

In the submodel describing respiration, the growth of two groups of heterotrophic strict aerobic bacteria, of which a part is capable to grow under anaerobic conditions with nitrate as electron acceptor, was calculated by a first order rate equation. (The model was originally developed to simulate denitrification in the anaerobic part of the aggregate.) The relative growth rate was described by a double Monod equation consisting of rate limiting factors for carbon substrate and oxygen electron acceptor. Changes in the amounts of oxygen and glucose carbon were described by Pirt's equation (Pirt, 1975), where growth yields and maintenance coefficients of the bacteria are distinguished. The release of carbon dioxide was calculated from the difference of the consumption rate of glucose and the rate of carbon used to form biomass. Thus it was assumed that complete oxidation of the organic matter occurred. The microorganisms were assumed to be immobile (Woldendorp, 1981) and active. The environmental conditions that affect growth and respiration, i.e. organic matter content and electron acceptor, were assumed to equal the concentrations of these substances in the water phase of the soil. Soil water content will thus have a profound influence on these concentrations. First, different concentrations directly affect relative growth rates through the Monod equation. Second, low water contents will decrease the rate of diffusion over short distances (microdiffusion) of nutrients to bacterial colonies or cells. The submodel was developed for a homogeneous soil layer. In the simulation model each concentric layer of the aggregate was also assumed homogeneous. Therefore, the respiration submodel could simply be applied in each layer of the aggregate to yield all of the production terms $P_{i}$ in eq. 1 .

\section{Water transport submodel}

Water redistribution in the aggregate was calculated by combining Darcy's law, eq. (2): 


$$
J_{\mathrm{w}}=-k \cdot \frac{\mathrm{d} h}{\mathrm{~d} x}
$$

with the continuity equation, eq. (1), where the production term cancelled because roots were absent. Since only horizontal transport of water occurred in the aggregate, gravitational head was omitted in eq. (2). Both hydraulic conductivity $(k)$ and pressure head of soil water $(h)$ were functions of volumetric water content $(\theta)$.

In the experiments (Fig. 4) it appeared that redistribution of water with an initial (schematic) distribution as depicted in Fig. 1b, resulted finally in a non-homogeneous radial distribution of water. This was attributed to the hysteresis phenomenon that may especially occur in the water retention curve (Koorevaar et al., 1983). Preliminary attempts to model the redistribution process of water in the aggregate without taking hysteresis into account failed, because water content was always finally homogeneously distributed. Thus, the submodel for water redistribution had to include hysteresis.

A simulation model describing soil water flow including hysteresis in the water retention curve was reported by Dane and Wierenga (1975). Essentially, the scanning curve for wetting (or drying) was forced to converge to the main wetting (or main drying) curve as a function of the difference between the water content at which a reversal of drying to wetting (or wetting to drying) occurred, and the actual water content. The model was attractive to use because it combined a reasonable description of the hysteresis phenomenon (drawn from tests of the hysteresis function on literature data) with an explicit computational scheme similar to that used in the present simulation model. Dane and Wierenga's model was reformulated so that variable time step integration methods could be used to save computer time. Furthermore, the tabular data input of the main drying and main wetting water retention curves and the hydraulic conductivity-water content curves in the model was replaced by equations described by Van Genuchten (1980). The parameters in these equations were estimated from measured data by procedures outlined by Van Genuchten (1978).

The water submodel is not affected by the results of other submodels, though in real soil hydraulic characteristics may be affected by entrapped air and gas pressure (Chahal, 1966), resulting from gas production and consumption processes; the water submodel, however, directly affects the submodels for the transport processes of solutes and gases.

\section{Solute-transport submodel}

Solute transport in the aggregate was calculated by combining eq. (3): 
$J_{\mathrm{w}}=-D_{0} \cdot \lambda_{\mathrm{w}} \cdot \theta \cdot \frac{\mathrm{d} c_{s}}{\mathrm{~d} x}-L_{\mathrm{d}} \cdot\left|J_{\mathrm{w}}\right| \cdot \frac{\mathrm{d} c_{s}}{\mathrm{~d} x}+J_{\mathrm{w}} \cdot c_{\mathrm{s}}$

with the continuity equation, eq. (1). The three terms in eq. (3) represent Fick's first law for diffusive transport, convective dispersion, and convective transport of the solute, respectively. The diffusive flux in soil is reduced compared with that in free water, because the water phase occupies only a fraction of the soil volume $(\theta)$, and the diffusion path has a tortuous geometry $\left(\lambda_{\mathrm{w}}\right)$. The tortuosity factor, $\lambda_{w}$, is an empirical function of the volumetric water content, $\theta$. The convective dispersion coefficient, $L_{\mathrm{d}} \cdot\left|J_{\mathrm{w}}\right|$, is linearly related to the average water flow velocity, $\left|J_{\mathrm{w}}\right|$ (Bolt, 1979). The concentration of solute $\left(c_{\mathrm{s}}\right)$ refers to the water phase of the soil, for no adsorption of solutes to the solid phase is assumed to occur. Numerical dispersion was reduced in the simulation program by computing the convective transport (third term in eq. 3 ) using the linearly interpolated value for $c_{\mathrm{s}}$ at the transition between adjacent compartments (Goudriaan, 1973).

Equation (3) was derived and extensively discussed by Bolt (1979), and it has been applied in numerous simulation studies, e.g. Leistra $(1972,1980)$, Frissel and Reiniger (1974), De Wit and van Keulen (1975), Leistra et al. (1980) and Boesten (1986).

It follows directly from eq. (3) that the water flow submodel affects the transport of the solutes as long as the redistribution process continues; diffusive transport, however, will always be present in moist soil, since bacterial activity will hardly ever be similar in adjacent compartments.

\section{Gas-transport submodel}

Gas transport in the aggregate was calculated by combining eq. (4):

$J_{\mathrm{g}}=-D_{i j} \cdot \lambda_{\mathrm{g}} \cdot \epsilon_{\mathrm{g}} \cdot \frac{\mathrm{d} c_{\mathrm{g}}}{\mathrm{d} x}+J_{\mathrm{p}} \cdot \frac{c_{\mathrm{g}}}{c}$

with the continuity equation, eq. (1). The first term in eq. (4) represents Fick's first law for diffusive transport incorporating area reduction $\left(\epsilon_{\mathrm{g}}\right)$ and tortuosity $\left(\lambda_{\mathrm{g}}\right)$, similar to solute transport, but now referring to the gas phase of soil. The binary diffusion coefficients, $D_{i j}$, were calculated as described previously (Leffelaar, 1987). When eventually pressure changes occurred, the binary diffusion coefficients were pressure corrected. Diffusive transports through the water phase of soil were calculated according to Fick's first law, i.e. the first term in eq. (4), under the assumption that no coupling of gas fluxes will occur in water. This seems plausible, because the main interactions of dissolved gases will be with the water molecules: water density is about three orders of magnitude higher compared with dissolved gas densities. 
The second term in eq. (4) is the product of the pressure adjustment flux $\left(J_{\mathrm{p}}\right)$ and the relative presence of gas $g\left(c_{\mathrm{g}} / c\right)$, that serves to maintain equal total gas pressures on either side of adjacent soil layers. In fact, the second term in eq. (4) embodies the coupling of fluxes in multinary gas mixtures where water is absent (Leffelaar, 1987). The description of diffusion of gases by eq. (4) in multinary, isothermal, isobaric, ideal-gas mixtures, where in principle differences in total gas pressure were caused solely by unequal binary diffusion coefficients $\left(D_{i j}\right)$, agreed to within $10 \%$ with results of the rigorous gas kinetic theory for such systems (Leffelaar, 1987). The pressure adjustment flux in that case was calculated as the sum of the individual gas fluxes. The integration of the multinary gas diffusion model in the models for water flow and respiration complicates the calculation of the pressure adjustment flux. This is so, because in a wet soil, where water movement occurs, differences in total gas pressure could also be caused by different gas solubilities in water, mass flow of gas due to water movement, and different source/sink terms in adjacent soil layers, aside from the effect of unequal binary diffusion coefficients. To calculate the pressure adjustment flux in the integrated model, the previously used assumption that total gas pressure gradients will not occur in adjacent soil layers (Leffelaar, 1987), was supplemented with the assumption that partitioning of gases over the water and the gas phase is instantaneous and given by the gas solubility coefficients in water. Essentially, the total gas pressure in adjacent gas-continuous layers, i.e. layers that have gasfilled porosities exceeding a certain critical value $\epsilon_{\mathrm{g}}^{\text {crit }}$, is kept constant by allowing the gas to flow instantaneously between these layers. $\epsilon_{\mathrm{g}}^{\text {crit }}$ is assumed to be the value where air permeability is just measurable (Le Van Phuc and Morel-Seytoux, 1972). When the initial distribution of water in soil is such that in the outer layers $\epsilon_{\mathrm{g}}<\epsilon_{\mathrm{g}}^{\text {crit }}$, gas exchange takes place via the water phase, and the total gas concentrations in these layers will undoubtedly be different from the enclosed gas-continuous layers. As water redistributes, layers at the water front will become gas-continuous, and a jump in total gas concentration will appear. When also the outer layer becomes gas-continuous, such a jump in total gas concentration will occur at the interface of the aggregate and the surroundings. The instantaneous adjustment may be compared with the flow of bubbles that sometimes occurs from a swamp or when air from an immersed aggregate is suddenly searching its way out (Stroosnijder and Koorevaar, 1972).

Full details to solve the pressure adjustment flux in the integrated model were given by Leffelaar (1988).

Numerical calculations were done by a program writfen in Continuous System Modeling Program III (CSMP III) language (IBM, 1975), using the variable time step integration method of Runge-Kutta Simpson, and executed on a VAX machine. 


\section{Model parameters}

The procedure followed to assess the simulation model was similar to the one proposed by Leffelaar and Wessel (1988): data not measured during the present study were gathered from different authors, and then it was investigated whether it was possible to simulate the overall picture of the experiment by modifying some of the gathered data within reasonable limits.

\section{Aggregate characteristics}

The initial volume of the chamber that contained the aggregate for the reported experiment was $530 \mathrm{~cm}^{3}$. Aggregate dimensions were those of the experimental system: height and diameter 2.59 and $9.8 \mathrm{~cm}$, respectively. Fourteen concentric layers were distinguished to characterize the space coordinate of the model aggregate: 5 layers of $0.2 \mathrm{~cm}, 2$ of $0.3 \mathrm{~cm}, 2$ of $0.4 \mathrm{~cm}$, and 5 of $0.5 \mathrm{~cm}$. The choice of both number and grouping of layers was based on a compromise between the need to simulate the expected large gas concentration gradients in the wet outer soil layers with reasonable accuracy, and to optimize the time step used for the Runge-Kutta Simpson integration method both with respect to maintaining numerical stability and to minimize roundoff errors in this single precision integration algorithm. Soil porosity, 0.478 $\mathrm{cm}^{3} \mathrm{~cm}^{-3}$, was calculated from the volume and amount of soil, using a particle density of $2.65 \mathrm{~g} \mathrm{~cm}^{-3}$. Gas pressures in the soil layers and in the chamber that contained the aggregate were initiated according to the gas composition used to flush the respirometer system: $19.525 \mathrm{kPa}$ and $81.8 \mathrm{kPa}$ for oxygen and neon, respectively. Neon was used so that molecular nitrogen from denitrification could be measured. The amount of solution added to the aggregate at the start of the simulation was $43.2 \mathrm{~cm}^{3}$; it contained $3.0 \mathrm{~g} \mathrm{l}^{-1}$ of glucose and $8.44 \mathrm{~g} \mathrm{l}^{-1}$ of potassium nitrate, so that the amounts of $\mathrm{C}$ and $\mathrm{N}$ applied were similar to those in the experiment.

\section{Microbiological characteristics}

The model also contains a routine to describe anaerobic respiration due to denitrification, the process where nitrite, nitrous oxide and molecular nitrogen are formed from nitrate. The parameterization of the anaerobic part was described in Leffelaar and Wessel (1988), while the parameterization for the aerobic part was given in Leffelaar (1988).

Some essential parameters used are: initial amount of biomass: $10^{-5} \mathrm{~kg} \mathrm{C}$ per $\mathrm{kg}$ of dry soil; maximum relative growth rate $0.75 \times 10^{-5} \mathrm{~s}^{-1}$; the half saturation value for oxygen respiration in water saturated soil crumbs: $10^{-3}$ $\mathrm{mol} \mathrm{O}_{2} \mathrm{~m}^{-3} \mathrm{H}_{2} \mathrm{O}$ (Greenwood, 1961 ); half saturation value on glucose: 0.0174 $\mathrm{kg} \mathrm{C} \mathrm{m}{ }^{-3} \mathrm{H}_{2} \mathrm{O}$ (Shah and Coulman, 1978); maximum growth yields and maintenance coefficients on glucose as carbon source with oxygen as electron acceptor: $0.503 \mathrm{~kg} \mathrm{~B} \mathrm{~kg}^{-1} \mathrm{C}$ and $0.212 \times 10^{-5} \mathrm{~kg} \mathrm{C} \mathrm{kg}^{-1} \mathrm{~B} \mathrm{~s}^{-1}$, respectively; 
similar values for oxygen (needed to calculate the oxygen consumption rate) were $0.65 \mathrm{~kg} \mathrm{~B} \mathrm{~kg}^{-1} \mathrm{O}_{2}$ and $0.382 \times 10^{-5} \mathrm{~kg}^{-1} \mathrm{O}_{2} \mathrm{~kg}^{-1} \mathrm{~B} \mathrm{~s}^{-1}$, respectively.

\section{Hydraulic characteristics}

Initial water distribution was given by the water content measurement at the start of the experiment, Fig. 4. The main water retention curves and the hydraulic conductivity curves for the sandy loam soil from Lelystad are depicted in Fig. 3. Experimental details were given by Leffelaar (1988). The dashed water retention curves in Fig. 3 were obtained by the optimization procedures by Van Genuchten (1978); the continuous hand-drawn envelop curves produced the best agreement between measured and simulated water contents, however. Therefore, these were used to produce the data presented below. Assuming that the aggregate followed the main drying curve before the solution was added, initiation of pressure head in each compartment was carried out according to the primary wetting scanning curve that is also shown in Fig. 3. To calculate the scanning curves, a hyperbolic type of equation:

$y=a /\left(\left|\theta-\theta_{T}\right|+a\right)$

was used (Dane and Wierenga, 1975): when the difference between the water content where a reversal from e.g. drying to wetting occurs $\left(\theta_{T}\right)$ and the ac-

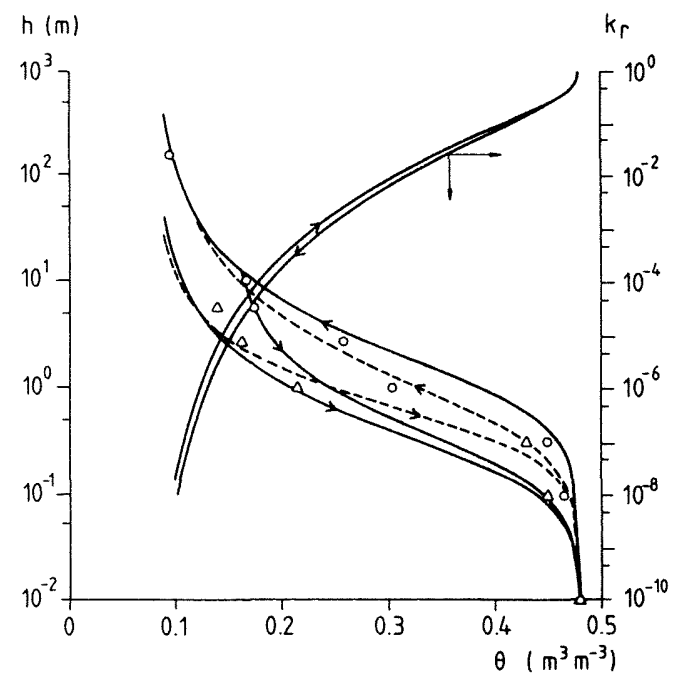

Fig. 3. Experimental ( $O$ : desorption; $\triangle$ : sorption), curve-fitted (dashed line, Van Genuchten, 1978 ), and hand-drawn envelope (solid line) soil water retention curve that produced the best agreement between measured and simulated water contents, and primary wetting scanning curve used for initiation of model; calculated (solid line, Van Genuchten, 1978) relative hydraulic conductivity curves based on hand-drawn water retention curves, for the Lelystad sandy loam. 
tual water content $(\theta)$ equals $a$, the scanning curve is halfway between the main water retention curves. The pressure head at the actual water content is then given by the sum of the pressure head at the main drying curve times $y$, and the main wetting curve times $(1-y)$. Parameter $a$ in the hyperbola was taken as $0.01 \mathrm{~m}^{3} \mathrm{~m}^{-3}$ (Dane and Wierenga, 1975).

The hydraulic conductivity-water content curves in Fig. 3 were calculated from the envelop water retention curves by procedures outlined by Van Genuchten (1978): these calculations gave the relative hydraulic conductivity curves, however, and a matching point was needed, e.g. the saturated hydraulic conductivity. The saturated hydraulic conductivity, $5 \times 10^{-7} \mathrm{~m} \mathrm{~s}^{-1}$, was obtained following the constant head method described by Kessler and Oosterbaan (1974). Preliminary simulation runs showed that the rate of water redistribution hardly affected the course of other processes since gas-continuity between the aggregate and the surroundings did not occur at the final water distribution. Therefore, solely to reduce computer time, the saturated hydraulic conductivity was taken as 5 times smaller.

\section{Transports characteristics in the water phase}

The diffusion coefficient for glucose at $25^{\circ} \mathrm{C}$ was $6.7 \times 10^{-10} \mathrm{~m}^{2} \mathrm{~s}^{-1}$ (Harremoës, 1978). Diffusion coefficients at about $20^{\circ} \mathrm{C}$ for oxygen, carbon dioxide, and molecular nitrogen in water were $20 \times 10^{-10}, 16.5 \times 10^{-10}$, and $22 \times 10^{-10} \mathrm{~m}^{2} \mathrm{~s}^{-1}$, respectively (Harremoës, 1978). From the preliminary simulation runs it appeared that hardly any gaseous exchange between the interior of the aggregate and the surroundings occurred when these literature data were used. The experimental findings, however, show that exchange of gases between the aggregate and the surroundings was much more pronounced. Assuming that gaseous transports through the water phase of soil were well described, it seems probable that in the experimental aggregate these transports were enhanced, e.g. through small cracks in the outer part of the aggregate or perhaps along the top cover of the soil container (see Fig. 2). In an attempt to take account of this enhancement in gaseous exchange, the diffusion coefficients of gases in water were set 10 times higher compared with the literature values for pure water. Gas solubility coefficients at $20^{\circ} \mathrm{C}$ and 1 atmosphere for oxygen, carbon dioxide, molecular nitrogen, and neon were reported by Wilhelm et al. (1977). The relationship between the tortuosity factor for diffusion of solutes and gases in the water phase and soil water content were taken from a literature compilation by Leistra (1978). The value for the dispersion length $\left(L_{\mathrm{d}}\right)$ for this fine packed soil was suggested by Prof. G.H. Bolt (pers. commun.) as $0.001 \mathrm{~m}$.

Transport characteristics in the gas phase

Parameters and equations needed to calculate binary diffusion coefficients were reported previously (Leffelaar, 1987). As a first approximation, the tortuosity factor for diffusion of gases in the gas phase, $\lambda_{\mathrm{g}}$, was represented by 
the same relationship as the one used for solutes in the water phase: for the gases it was related to the gas-filled porosity, however. The value for the gasfilled porosity where soil was considered gas-continuous, $\epsilon_{\mathrm{g}}^{\text {crit }}$, was taken as $0.063 \mathrm{~m}^{3} \mathrm{~m}^{-3}$. This value was simply just sufficient to prevent gas continuity throughout the aggregate. The preliminary simulations showed that when $\epsilon_{\mathrm{g}}^{\text {crit }}$ was taken slightly smaller, gas continuity occurred and anaerobiosis quickly disappeared: such results were contradictory to the experimental findings and it was thus concluded that no gas-continuity had occurred in the experiment. The value of about $6 \%$ for the critical gas-filled porosity was near to experimental values found by Le Van Phuc and Morel-Seytoux (1972), and Corey (1957).

\section{RESULTS AND DISCUSSION}

One representative experimental data set on the distribution of water and gases is presented in Figs. 4, 5 and 6 for the Lelystad sandy loam soil, in which the anaerobic process of denitrification, which also produces $\mathrm{CO}_{2}$, could occur. Data points originate from the experiments, whereas the lines were produced by the simulation model.

Figure 4 shows the volumetric water distribution at the start of the experiment and at the end after 45 hours. The methods to measure water content were evaluated by comparing the water balance as calculated from the gamma ray attenuation method at the start and the end of the experiment with data from the gravimetric moisture measurement at the end. These yielded vol-

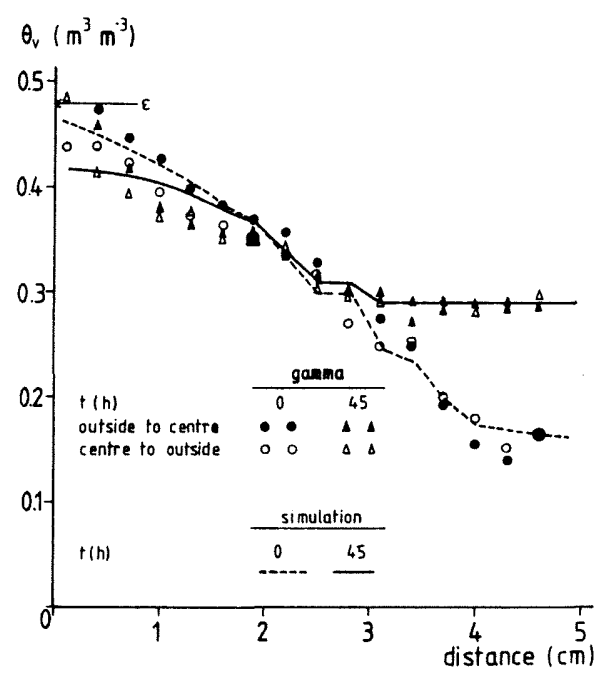

Fig. 4. Experimental and simulated volumetric water distribution in the soil aggregate (center at distance $4.9 \mathrm{~cm}$ ) at start and end of experiment. 
umes of $71.2 \pm 0.6,72.0 \pm 0.6$ and $71.0 \pm 0.7 \mathrm{ml}$, respectively, which was considered very satisfactory.

After about 24 hours water redistribution was complete (data not shown), even though a homogeneous volumetric water content $(0.363 \pm 0.008)$ was not attained. This indicates that a homogeneous suction distribution was attained in the soil aggregate combined with a heterogeneous water distribution due to hysteresis in the soil water characteristic. In the absence of hysteresis, the air-filled porosity at equilibrium $\left(0.115 \mathrm{~cm}^{3} \mathrm{~cm}^{-3}\right)$ would have been sufficient to let oxygen diffuse into the aggregate and to stop anaerobic processes. In the presence of hysteresis, however, a small amount of added water is sufficient to decrease gaseous diffusion to such an extent, that the oxygen consumption is not met, resulting in anaerobiosis. The volume of air-filled pores in the outer shell of the aggregate remained close to zero, even after 45 hours.

The simulated redistribution of the volumetric water distribution in Fig. 4 was essentially completed after 12 hours. The simulated curve is not smooth, since plotted water contents were obtained by weighing and summing the water contents of the concentric layers that coincided with a measuring location: thus plotted data refer to the rectangular geometry of the water measurements obtained by gamma radiation (De Swart and Groenevelt, 1971). The major portion of the simulated curve and the data points match well. At the outside of the aggregate, however, the simulated water content is about $3 \%$ lower than the experimental value, and consequently the air-filled porosity at the outside was that much higher. The critical air-filled porosity in the simulation was so chosen $\left(0.063 \mathrm{~cm}^{3} \mathrm{~cm}^{-3}\right)$, that no gas continuity would occur after the redistribution of water, in accordance with the experimental findings. When the critical air-filled porosity was taken slightly lower, however, the aggregate became gas-continuous in the course of the simulation and anaerobiosis disappeared quickly. It thus appears that air-filled porosity is a determining factor in the regulation of oxygen status of soil, at least at the micro-scale.

Figure 4 shows that the exchange of gases between the soil and the gas collection circuit took place through the water phase, and it was expected that the aggregate would remain anaerobic after the oxygen in its interior was consumed. Figure 5 confirms this expectation. The data points show oxygen pressure in the aggregate center to equal zero after 13 hours, while the peripheral oxygen pressure remains about $2 \mathrm{kPa}$. Outside the aggregate, however, and after 45 hours, the amount of oxygen had decreased by only $19.5 \mathrm{ml}$ (Fig. 6), corresponding to an oxygen pressure of $15.7 \mathrm{kPa}$. Oxygen flux can be obtained by differentiating Fig. 6 with respect to time. Oxygen flux density is then obtained by dividing this quantity by the surface area of the aggregate $\left(79.7 \pm 1.0 \mathrm{~cm}^{2}\right)$. At 21 hours the oxygen flux density amounted to $2.7 \pm 10.8$ $1 \mathrm{O}_{2} \mathrm{~m}^{-2} \mathrm{day}^{-1}$ (the large confidence interval is discussed below). This value compares favourably with field measurements in bare soil (Russell, 1973).

Figure 6 also shows the evolution of carbon dioxide. The oxygen and car- 


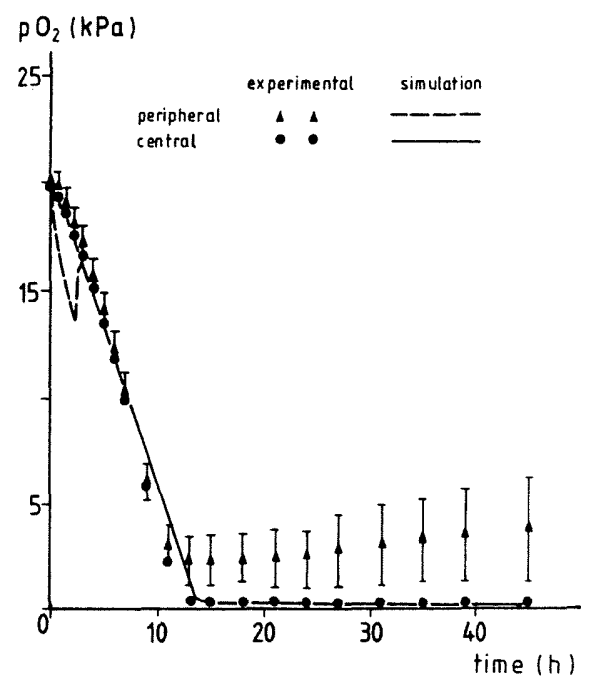

Fig. 5. Experimental and simulated oxygen pressure in center and $4 \mathrm{~cm}$ from center (peripheral) of soil aggregate as function of time.

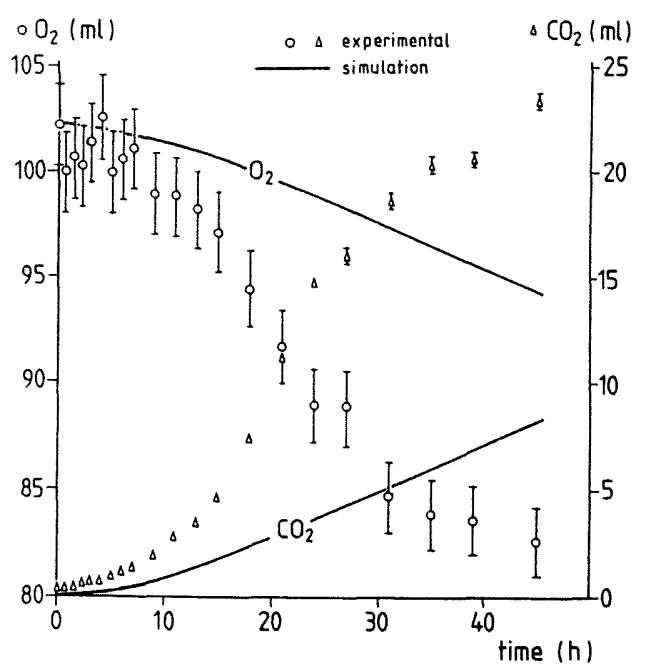

Fig. 6. Experimental and simulated volume of oxygen (left $y$-axis) and carbon dioxide (right $y$ axis) in gas collection circuit as function of time.

bon dioxide curves form complementary S-shaped curves. The amounts of oxygen consumed $(20 \pm 3 \mathrm{ml})$ and carbon dioxide produced $(23 \pm 0.5 \mathrm{ml})$ in 45 hours were practically the same. This resulted in a respiratory quotient, defined as the ratio of the volumetric rates of carbon dioxide production and oxygen consumption, of about one. In a partially anaerobic soil, however, 
only a portion of the soil is consuming oxygen, while the whole is producing carbon dioxide and the respiratory quotient is expected to exceed one. Therefore, the respiratory quotient is not a sensitive measure to decide whether a soil is partially anaerobic. Russell (1973) and Gliński and Stẹpniewski (1985), however, state the opposite with regard to the sensitivity of the respiratory quotient. The $\mathrm{CO}_{2}$ curve in Fig. 6 was also used to calculate the flux density at 21 hours and yielded $3.7 \pm 1.31 \mathrm{CO}_{2} \mathrm{~m}^{-2} \mathrm{day}^{-1}$. This value is of the same order of magnitude as field data of De Jong et al. (1979), though these authors measured $\mathrm{CO}_{2}$ evolution in a cropped soil. The confidence interval in the $\mathrm{O}_{2}$ consumption rate is large compared to that in the $\mathrm{CO}_{2}$ production rate. This is caused by the propagation of the error in the measured amount of $\mathrm{O}_{2}$ which is determined by the difference of two large numbers. The reasonable error in the measurement of $\mathrm{CO}_{2}$ makes it a more appropriate measure to assess soil activity.

Figure 5 shows the simulated results of oxygen pressures in the aggregate center and the periphery to equal about zero after $14 \mathrm{~h}$. The oxygen pressure curves show satisfactory similarity to the experimental findings. The experimental results of peripheral (triangles) and central (dots) electrodes coincided up to about 10 hours; after about 14 hours only the experimental results of the central electrode coincided with the simulated results. The simulated results show an interesting feature of the model: when the layer where the peripheral oxygen electrode is located becomes gas-continuous after about 2.5 hours, a pressure jump occurs. Hereafter, the simulated results of both the electrodes coincide. The feature of the pressure jump has a number of aspects. First, the oxygen pressure in the layer that has become gas continuous was about $4 \mathrm{kPa}$ lower than in the adjacent series of gas-continuous layers before the pressure jump occurred; hardly any gradient in oxygen pressure occurred in these adjacent gas-continuous layers. Thus, gaseous transport through the water phase was very limited. Second, this jump or a more gradual change in oxygen pressure was not found in the experimental results. Therefore, it is very probable that internal gas-continuity has been present in the layers where the oxygen electrodes were located in the experiment, resulting in similar electrode readings. Third, such pressure jumps focus attention to the practical problem of measuring oxygen pressure by polarographic Clark-type oxygen electrodes. The calculated absolute pressure in the layer that became gas-continuous was 86.9 and $103.9 \mathrm{kPa}$ before and after the jump, respectively. Since changes in absolute pressure cause proportional changes in oxygen pressure, Clark-type oxygen electrode measurements will be directly affected (Fatt, 1976).

Figure 6 shows that the oxygen outside the simulated aggregate decreased much slower than in the experiment. Oxygen decrease is determined by the respiration rate and the volume of the aerobic outer shell of the aggregate, Fig. Ib. Introduction of higher aerobic respiration rates in an attempt to bet- 
ter match the experimental decrease of oxygen in the soil container, however, caused a proportionally faster decrease of the oxygen pressures at the locations of the electrodes. Thus, the enhancement in gaseous exchange between the aggregate and the surroundings was stronger than that attained by the 10 times higher diffusion coefficients in the water phase (see section about model parameters), and a greater part of the soil volume did participate in oxygen respiration in the experiment. The ratio of oxygen flux density at $21 \mathrm{~h}$ in the experiment $\left(2.71 \mathrm{O}_{2} \mathrm{~m}^{-2}\right.$ day $\left.^{-1}\right)$ to that of the simulation $\left(0.611 \mathrm{O}_{2} \mathrm{~m}^{-2}\right.$ $\mathrm{day}^{-1}$ ) would suggest that the aerobic shell in the experiment was about four times larger than that in the simulation. Since oxygen penetration in the simulation equalled about $0.2 \mathrm{~cm}$, this would mean that in the experiment oxygen penetrated into the aggregate to a depth of about $0.8 \mathrm{~cm}$. This is very near to the peripheral electrode, that in fact stabilized at about $2 \mathrm{kPa}$ in the experiment, Fig. 5.

Figure 6 also shows the evolution of carbon dioxide. It is seen that the simulated curve lags behind compared with the experimental one, similarly as in the case of the oxygen curve. This will be caused in part by the low carbon dioxide transport rate, and in part by a similar reasoning as in the case of oxygen: due to low gas transport rates, the aerobic soil volume participating in aerobic respiration will be smaller, and thus carbon dioxide production under aerobic conditions will be lower, and a smaller amount of this gas is transported into the soil container. Though the simulated curve lags behind compared with the experimental one, it is near complementary to the simulated oxygen curve, resulting in a respiration quotient of about one, similar to the experimental data. In fact, the respiration quotient behaved as a damped oscillation $(0.4(1 \mathrm{~h}) \rightarrow 1.27(8 \mathrm{~h}) \rightarrow 1.44(12 \mathrm{~h}) \rightarrow 0.97(23 \mathrm{~h}) \rightarrow 1.0(28$ h) ) and stabilized after 28 hours. One would expect higher final values, however, since the whole of the aggregate was producing carbon dioxide, while only the outer shell consumed oxygen. However, it appeared that a model run in which no anaerobiosis occurred, gave a stable respiration quotient of about 0.45 . This implies (1) the aerobic RQ is too low for the organic matter used (glucose) and some of the microbiological parameters should be assessed anew, and (2) an RQ of 1 under partially anaerobic conditions in the model indicates anaerobiosis. When the literature values of the gas diffusion coefficients were used the sequence of respiration quotients was $(0.4(1 \mathrm{~h}) \rightarrow 0.6$ $(3 \mathrm{~h}) \rightarrow 0.9(11 \mathrm{~h}) \rightarrow 1.66(16 \mathrm{~h}) \rightarrow 2.44(45 \mathrm{~h}))$, and no stabilization occurred. These simulated findings demonstrate a strong influence of transport processes on the respiration quotient of soil. This leads to the conclusion that the respiration quotient is not a sensitive measure to decide whether a soil is partially anaerobic.

No experimental microbiological data could be gathered till now. 


\section{CONCLUDING REMARKS}

The data presented show that the respirometer system enables us to measure the course in space and time of the state variables which determine the oxygen distribution in soil. For a full explanation of the relationships between the measured data, however, the simulation model describing the interactions between the active biomass, transport processes of water, gases, and nutrients, and storage factors like different solubilities of gases in soil water is needed. Thus, the measurements are gathered to evaluate the simulation model, but the simulation model is needed for a full, or at least a more complete, interpretation of the measured data. The model gives a satisfactory description of the soil biological system studied: part of the experimental results could be described quantitatively, e.g. water distribution and the time course of the oxygen pressure at the experimental positions of the electrodes, whereas other data that deviated from the experimental data, e.g. consumption rate of oxygen and production rates of carbon dioxide, could be understood by studying the dynamic behaviour of the model.

This study gives rise to the following conclusions about a number of physical soil properties that are usually not measured or considered in the soil physics literature with respect to biological processes in soil:

(1) the critical gas-filled porosity, $\epsilon_{\mathrm{g}}^{\text {crit }}$, below which gaseous transports take place only through the water phase, is a determining factor in gaseous exchange in soil;

(2) soil water hysteresis is important in causing a non-homogeneous soil water distribution at a homogeneous pressure head distribution, implying that a small amount of added water is sufficient to decrease the gas-filled porosity to values smaller than the critical gas-filled porosity;

(3) water redistribution has a significant effect on the biological processes only in so far as it determines the period during which there are no continuous air-filled pores open to the surface;

(4) soil respiration may cause differences in soil atmospheric pressure in the enclosed gas continuous part of the soil, which may affect soil hydraulic characteristics (Chahal, 1966);

(5) the exchange of gases between aggregate and surroundings is seriously underestimated when it is fully ascribed to diffusion through the water phase of gas-discontinuous soil layers: the model suggests that enhancement of gas exchange occurs, perhaps through small cracks in the outer part of the aggregate or along the top cover of the soil container;

(6) total gas pressure jumps, as simulated by the model, might affect the measurement of oxygen pressure by polarographic oxygen electrodes, though it remains to be investigated whether such pressure jumps will actually occur in field soil.

This study showed that the parameterization of the model is a major prob- 
lem that needs attention first. Therefore, a more extensive exploration of both the experimental respirometer system and the theoretical simulation model is intended: the model will be used first to plan experiments with respect to the respirometer system, second to help interpret the data so obtained, and third to investigate the relative importance of a number of parameters in a sensitivity analysis. Furthermore, the model may be used to study trends and interactions between biological activity and transport processes in the aggregate.

In this study the form of the aggregate was mathematically ideal and respiratory activity was homogeneously distributed in the soil. It depended only on environmental conditions that resulted from the interaction of biological activity and transport phenomena. This is why we could apply a model that calculates the dynamics of water, nutrients, oxygen and biological activity as a function of the distance from the outside of the aggregate. In field soils, no mathematically ideal forms exist and the question arises whether soil geometry as we find it in the field should be directly used in modelling, or that for instance an aggregated soil should be idealized in the form of porous spheres, as worked out by Smith $(1977,1980)$ and Leffelaar (1979), or that it would be most appropriate to develop a soil model that shows no visual, but a physical resemblance with the soil profile. An operational method that enables one to derive a model soil with similar diffusive properties as the soil it originates from, was developed by Rappoldt (1990). The starting point of his method is that for each point in the soil there is a shortest distance to the nearest macropore or crack. The distribution of these distances characterizes the geometry of the soil. A model system can now be derived that has the same distribution of distances as the real soil, but has a much simpler geometry. The model system consists of soil cylinders with different radii: small cylinders represent the soil mass near cracks; the larger cylinders represent the soil mass further away from the cracks. Diffusive transport in the real soil aggegates or structural elements is described then by solving a diffusion equation for the model system. Rappoldt also shows however, that a non-uniform distribution of soil activity seriously disturbs the correspondance between the anaerobic soil fraction and the distribution of distances (Rappoldt, 1992). This means that studies on the process level, as described in the present paper, have to be supplemented with studies describing the distribution of respiratory activity in soil.

\section{APPENDIX}


$c_{i} \quad$ concentration of substance $i$. When $i=\mathrm{g}$, it refers to gas, and units are either mol $\mathrm{m}^{-3}$ of gas phase or $\mathrm{mol} \mathrm{m}^{-3} \mathrm{H}_{2} \mathrm{O}$; when $i=\mathrm{s}$, it refers to solute, and unit is $\mathrm{kg} \mathrm{m}^{-3} \mathrm{H}_{2} \mathrm{O}$ total molar gas concentration in general, $c=\sum_{\mathrm{g}} c_{\mathrm{B}}$

amount $\mathrm{m}^{-3}$ $\mathrm{mol} \mathrm{m}^{-3}$

$C_{i} \quad$ concentration of substance $i$ with respect to volume of soil. When $i=\mathrm{g}$, it refers to gas, and amount is mol; when $i=\mathrm{s}$, it refers to solute, and amount is $\mathrm{kg}$; when $i=\mathrm{w}$, it refers to water, and amount is $\mathrm{m}^{3} \mathrm{H}_{2} \mathrm{O}$. Symbol is only used in the equation of continuity, eq. (1).

$D_{0} \quad$ diffusion coefficient of solute or gas in free liquid water

$D_{i j} \quad$ binary diffusion coefficient of gas pair $i-j$ in free air

$h$ pressure head of soil water. $h$ is a function of volumetric water content

$J_{i} \quad$ flux of substance $i$. When $i=\mathrm{g}$, it refers to gas, and amount is mol; when $i=\mathrm{s}$, it refers to solute, and amount is $\mathrm{kg}$; when $i=\mathrm{w}$, it refers to water, and amount is $\mathrm{m}^{3} \mathrm{H}_{2} \mathrm{O}$

$J_{\mathbf{p}} \quad$ pressure adjustment flux

$k$ hydraulic conductivity. $k$ is a function of volumetric water content

$L_{\mathrm{d}} \quad$ dispersion length parameter

$P_{i} \quad$ net production term of substance $i$. When $i=\mathrm{g}$, it refers to gas, and amount is mol; when $i=\mathrm{s}$, it refers to solute, and amount is $\mathrm{kg}$

pressure

gas constant

absolute temperature

time

space coordinate

weight factor: outcome of hyperbolic equation that forces a scanning curve towards one of the main water retention curves $(0 \leq y \leq 1)$

volumetric gas content

critical gas content where gas phase in layers is just discontinuous volumetric water content

turtuosity factor. When $i=\mathrm{w}$, tortuosity in water phase; when $i=\mathrm{g}$, tortuosity in gas phase. $\lambda_{\mathrm{w}}$ and $\lambda_{\mathrm{g}}$ are functions of $\theta$ or $\epsilon_{\mathrm{g}}$ respectively

bars around a variable means absolute value amount $\mathrm{m}^{-3}$ of soil

$\mathrm{m}^{2} \mathrm{~s}^{-1}$

$\mathrm{m}^{2} \mathrm{~s}^{-1}$

$\mathrm{m}$

amount $\mathrm{m}^{-2} \mathrm{~s}^{-1}$

$\mathrm{mol} \mathrm{m}^{-2} \mathrm{~s}^{-1}$

$\mathrm{m} \mathrm{s}^{-1}$

$\mathrm{m}$

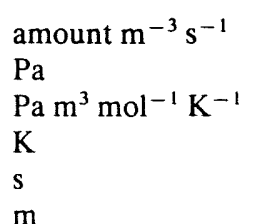

$\mathrm{m}^{3} \mathrm{~m}^{-3}$

$\mathrm{m}^{3} \mathrm{~m}^{-3}$

$\mathrm{m}^{3} \mathrm{~m}^{-3}$

\section{REFERENCES}

Allison, L.E. and Moodie, C.D., 1965. Carbonate. In: C.A. Black (Editor), Methods of Soil Analysis, Part 2. Agronomy 9. American Society of Agronomy, Madison, WI, pp. 13791396.

Bascomb, C.L., 1964. Rapid method for the determination of cation exchange capacity of calcareous and non-calcareous soils. J. Sci. Fd. Agric., 15: 821-823.

Berendts, B.Th., Blaauw, H.J.A., Harmsen, B.J.M., Smit, J.C. and Tijs, S.H., 1973. Foutenleer en Statistiek. Agon Elsevier, Amsterdam, 141 pp. 
Birch, H.F., 1958. The effect of soil drying on humus decomposition and nitrogen availability. Plant Soil, 10: 9-31.

Birch, H.F., 1959. Further observations on humus decomposition and nitrification. Plant Soil, 11: 262-286.

Boesten, J.J.T.I., 1986. Behaviour of herbicides in soil: simulation and experimental assessment. Dissertation, Agricultural University, Wageningen, 263 pp.

Bolt, G.H., 1979. Movement of solutes in soil: principles of adsorption/exchange chromatography. In: G.H. Bolt (Editor), Soil Chemistry B. Physico-chemical Models. Developments in Soil Science, 5B. Elsevier, Amsterdam, pp. 285-348.

Chahal, R.S., 1966. Effect of entrapped air and pressure on matric suction. Soil Sci., 102: 131134.

Corey, A.T., 1957. Measurement of water and air permeability in unsaturated soil. Soil Sci. Soc. Am. Proc., 21: 7-10.

Dane, J.H. and Wierenga, P.J., 1975. Effect of hysteresis on the prediction of infiltration, redistribution and drainage of water in a layered soil. J. Hydrol., 25: 229-242.

Day, P.R., 1965. Particle fractionation and particle-size analysis. In: C.A. Black (Editor), Methods of Soil Analysis, Part 1. Agronomy 9. American Society of Agronomy, Madison, WI, pp. 545-567.

De Jong, E., Redmann, R.E. and Ripley, E.A., 1979. A comparison of methods to measure soil respiration. Soil Sci., 127: 300-306.

De Swart, J.G. and Groenevelt, P.H., 1971. Column scanning with $60 \mathrm{keV}$ gamma radiation. Soil Sci., 112: 419-424.

De Wit, C.T. and Van Keulen, H., 1975. Simulation of transport processes in soils. Simulation Monographs, PUDOC, Wageningen, $100 \mathrm{pp}$.

Fatt, I., 1976. Polarographic oxygen sensors. CRC Press, Cleveland, $\mathrm{OH}, 278 \mathrm{pp}$.

Fillery, I.R.P., 1983. Biological denitrification. In: J.R. Freney and J.R. Simpson (Editors), Gaseous Loss of Nitrogen from Plant-Soil Systems. Martinus Nijhoff, The Hague, pp. 3364.

Frissel, M.J. and Reiniger, P., 1974. Simulation of accumulation and leaching in soils. Simulation Monographs. PUDOC, Wageningen, $116 \mathrm{pp}$.

Gliński, J. and Stępniewski, W., 1985. Soil aeration and its role for plants. CRC Press, Boca Raton, FL, 229 pp.

Goudriaan, J., 1973. Dispersion in simulation models of population growth and salt movement in the soil. Neth. J. Agric. Sci., 21: 269-281.

Greenwood, D.J., 1961. The effect of oxygen concentration on the decomposition of organic materials in soil. Plant Soil, 14: 360-376.

Harremoës, P., 1978. Biofilm kinetics. In: R. Mitchell (Editor), Water Pollution Microbiology, Vol 2. Wiley, New York, pp. 71-109.

IBM Corp., 1975. Continuous system modeling program III (CSMP III). Program reference manual. SH 19-7001-3. Data Processing Division, 1133 Westchester Ave., White Plains, N.Y.

Kessler, J. and Oosterbaan, R.J., 1974. Determining hydraulic conductivity of soils. In Drainage principles and applications. III. Surveys and investigations. ILRI, Wageningen, pp. 253296.

Koorevaar, P., Menelik, G. and Dirksen, C., 1983. Elements of Soil Physics. Developments in Soil Science, 13. Elsevier, Amsterdam, 228 pp.

Kreuzer, F., Kimmich, H.P. and Brezina, M., 1980. Polarographic determination of oxygen in biological materials. In: J. Koryta (Editor), Medical and Biological Applications of Electrochemical Devices. Wiley, New York, pp. 173-261.

Leffelaar, P.A., 1979. Simulation of partial anaerobiosis in a model soil in respect to denitrification. Soil Sci., 128: 110-120. 
Leffelaar, P.A., 1986. Dynamics of partial anaerobiosis, denitrification, and water in a soil aggregate: experimental. Soil Sci., 142: 352-366.

Leffelaar, P.A., 1987. Dynamic simulation of multinary diffusion problems related to soil. Soil Sci., 143: 79-91.

Leffelaar, P.A., 1988. Dynamics of partial anaerobiosis, denitrification, and water in a soil aggregate: simulation. Soil Sci., 146: 427-444.

Leffelaar, P.A. and Wessel, W.W., 1988. Denitrification in a homogeneous, closed system: experiment and simulation. Soil Sci., 146: 335-349.

Leistra, M., 1972. Diffusion and adsorption of the nematicide 1,3-dichloropropene in soil. PUDOC, Wageningen, $105 \mathrm{pp}$.

Leistra, M., 1978. Computed redistribution of pesticides in the root zone of an arable crop. Plant Soil, 49: 569-580.

Leistra, M., 1980. Transport in solution. In: R.J. Hance (Editor), Interactions between Herbicides and the Soil. Academic Press, London, pp. 31-58.

Leistra, M., Bromilow, R.H. and Boesten, J.J.T.I., 1980. Measured and simulated behaviour of oxamyl in fallow soils. Pestic. Sci., 11: 379-388.

Le Van Phuc and Morel-Seytoux, H.J., 1972. Effect of soil air movement and compressibility on infiltration rates. Soil Sci. Soc. Am. Proc., 36: 237-241.

Mebius, L.J., 1960. A rapid method for the determination of organic carbon in soil. Anal. Chim. Acta, 22: 120-124.

Novozamsky, I., Houba, V.J.G., Temminghoff, E. and van der Lee, J.J., 1984. Determination of "total" $\mathrm{N}$ and "total" $\mathrm{P}$ in a single soil digest. Neth. J. Agric. Sci., 32: 322-324.

Pirt, S.J., 1975. Principles of Microbe and Cell Cultivation. Blackwell, Oxford, $274 \mathrm{pp}$.

Rappoldt, C., 1990. The application of diffusion models to an aggregated soil. Soil Sci., 150: 645-661.

Rappoldt, C., 1992. Diffusion in aggregated soil. Dissertation, Agricultural University, Wageningen, $161 \mathrm{pp}$.

Russell, E.W., 1973. Soil Conditions and Plant Growth. Longman, London, 849 pp.

Shah, D.B. and Coulman, G.A., 1978. Kinetics of nitrification and denitrification reactions. Biotechnol. Bioeng., 20: 43-72.

Smith, K.A., 1977. Soil aeration. Soil Sci., 123: 284-291.

Smith, K.A., 1980. A model of the extent of anaerobic zones in aggregated soils and its potential to estimates of denitrification. J. Soil Sci., 31:263-277.

Stroosnijder, L. and Koorevaar, P., 1972. Air pressure within soil-aggregates during quick wetting and subsequent "explosion". Mededelingen Rijksfaculteit Landbouwwetenschappen Gent, 37(3): 1095-1106.

Van Genuchten, M.Th., 1980. A closed-form equation for predicting the hydraulic conductivity of unsaturated soils. Soil Sci. Soc. Am. J., 44: 892-898.

Van Genuchten, R., 1978. Calculating the unsaturated hydraulic conductivity with a new, closedform analytical model. Research Report 78-WR-08, Water Resources Program, Dep. of Civil Engineering, Princeton Univ., Princeton, NJ.

Wilhelm, E., Battino, R. and Wilcock, R.J., 1977. Low-pressure solubility of gases in liquid water. Chem. Rev., 77: 219-262.

Woldendorp, J.W., 1981. Nutrients in the rhizosphere. Agricultural yield potentials in continental climates. Proc. 16th Coll. Int. Potash Institute, Bern: 99-125. 